\title{
Aspects of visual argument: A study of the March of Progress
}

\section{CAMERon Shelley University of Michigan}

\begin{abstract}
The so-called March of Progress depicts human evolution as a linear progression from monkey to man. Shelley (1996) analyzed this image as a visual argument proceeding through "rhetorical" and "demonstrative" modes of visual logic. In this paper, I confirm and extend this view of visual logic by examining variations of the original March image. These variations show that each mode of visual logic can be altered or isolated in support of new conclusions. Furthermore, the March can be included in a visual "frame" to produce new arguments, much as a verbal argument can be made a component of a new and larger argument.
\end{abstract}

\begin{abstract}
Résumé: L'image de l'évolution humaine intitulée «La marche» se présente comme un progrès linéaire du singe a l'homme. Shelley (1996) interprète cette image comme un argument visuel qui emploie des modes rhétoriques et démonstratifs de la logique visuelle. Dans cet essai j'examine des variations de cette image pour confirmer et porter plus loin cette notion de la logique visuelle. Ces variations démontrent que chaque mode de logique visuelle peut se modifier et s'isoler pour appuyer des nouvelles conclusions. En plus, "La marche» peut s'insérer dans un cadre non visuel pour produire des nouveaux arguments un peu comme des arguments verbaux peuvent faire partie d'un argument nouveau et plus long.
\end{abstract}

Keywords: anthropology, demonstrative mode of visual argument, evolution, frame, March of Progress, thetorical mode of visual argument, visual argument, visual imagery.

\section{Introduction}

The so-called March of Progress, a depiction of human evolution as a linear progression from monkey to man, first appeared in the Time-Life book Early Man (Howell 1965, pp. 41-5). Since then, it has become one of the most widely recognized and dispersed icons of evolutionary biology (see Gould 1989, pp. 30-6). At the same time, it conveys a false impression about the nature of human evolution, that it may be viewed as an instance of progress through successive stages towards a future goal. Shelley (1996) provides an analysis of the March of Progress (hereafter, the $M a r c h$ ), characterizing the image as a visual argument and the false impression as the result of a fallacious conclusion.

In particular, Shelley argues that this conclusion may be understood as the result of an unfortunate combination of two modes of visual argument apparent in the March, namely the rhetorical and demonstrative modes. (Not to be confused with enthymemes and proper deductions as defined by Aristotle.) In the rhetorical mode, an image supports some conclusion by activating the viewer's concepts in 
roughly the same manner as an informal, verbal argument (see Groarke 1996, and also Olson 1991 and Moser 1996). In the demonstrative mode, an image supports some conclusion by appealing to the viewer's visual competence, that is, the so-called mind's eye (cf. Giere 1996). By this view, the March demonstratively suggests a set of changes in hominid physical stature that it rhetorically explains as progress in quality.

This analysis is plausible as far as it goes but remains in need of further support and extension. It would be helpful, for example, to find images in which the demonstrative and rhetorical modes of argument found in the March occur more or less in isolation. Such a find would tend to confirm the places imputed to them in the original image. Also, it would be helpful to find images in which the March is combined with other visual images to form new arguments with novel conclusions. Verbal arguments, after all, have the property that they may be incorporated into larger arguments containing new premises so that new conclusions are generated. The understanding of the March as a visual argument would be elucidated if it could be shown to have a similar property. Fortunately, due to the popularity of the March, there are many related images (descendants, in fact) available for examination. The aim of this article, then, is to present and analyze descendants of the original image to see whether its argumentative components can be isolated and whether those components can be revised and/or combined with new images to form new arguments. Section 2 briefly reviews the analysis of the March itself, followed by the analysis of two related images in Section 3 that isolate its demonstrative and rhetorical aspects. Section 4 presents a discussion of three of its offspring in which the March is adapted to argue for new conclusions. Although focused on aspects of one image, this case study suggests that the study of visual arguments may be generalized to many further visual presentations.

\section{The March as a visual argument}

A representation of the March is given in Figure 1. Shreeve (1995, p. 13) gives an excellent description of the message that this image is usually understood to convey:

[From the first, simian figures at the left,] a handful of hairy intermediates marches awkwardly, inevitably, toward the future, each with its posture a little better and its brain a little bigger than the one just behind it in line. The transformation along the way is mesmerizing. You watch humanity unfold like a flower, each ancestor the ripened promise of the one that came before.

This description cites a mixture of elements both visual and non-visual that combine to leave the final impression.

In the demonstrative mode, this image is construed iconically, as if it were a representation of a real process that the viewer can see in action. Each figure appears to be a point in this process, read from left to right, like the frames of a 


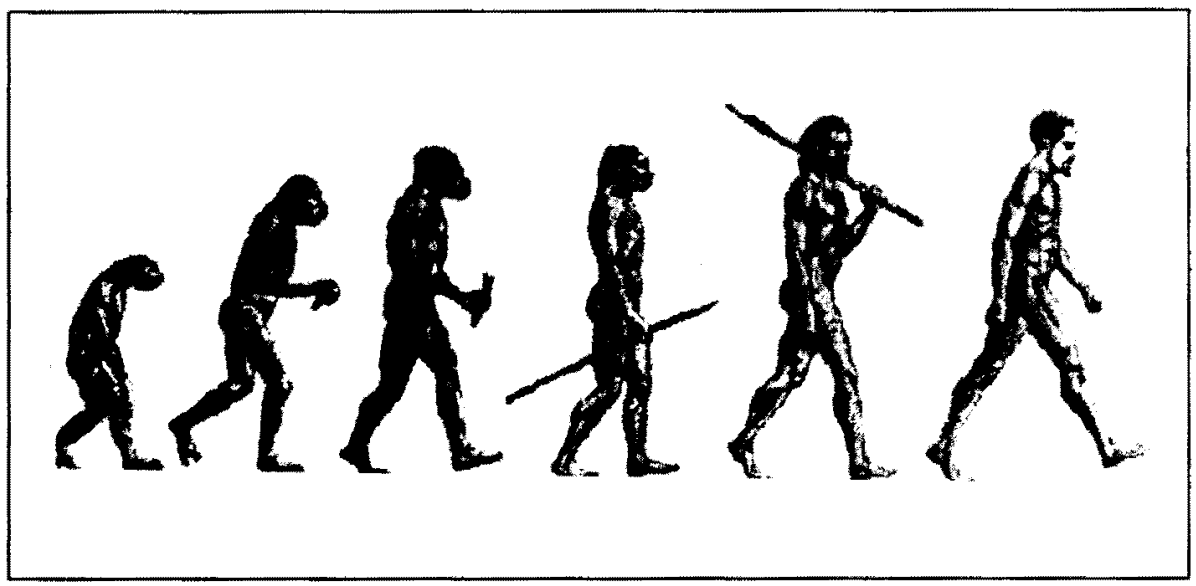

Figure 1. The March of Progress by Steven Jeffrey. This picture resembles the first such illustration, The road to Homo sapiens, by R. Zallinger (Howell 1965). The individuals represent, from left to right, Australopithecus, Homo habilis, Homo erectus, Neandertal man, Early modern man, and Modern man.

movie. The rough similarity in posture and outline of all the figures leaves the impression that they form a coherent group, in virtue of the Gestaltist law of similarity. At the same time, there are obvious differences in appearance between each figure and its neighbors in the sequence. In fact, these differences appear to form systematic, visual trends by which each figure is transformed, as Shreeve puts it, into its neighbor. For example, a consistent increase in the size of the braincase is evident, along with a coincident flattening of the face. The head is brought progressively backward over the torso so that the body of each hominid becomes more and more upright. There is a constant increase in body height and length of the stride. Each of these trends is an apparent relationship between each hominid and its ancestor that scientists might well be called upon to explain in terms of adaptation to changes in diet, locomotion, environment and so on. Unfortunately, since all the figures are depicted outside of their contemporary contexts, the March image does not even hint at such explanations.

In the rhetorical mode, we construe this image by finding a coherent interpretation of the concepts that it activates. And the March activates some very significant concepts. For example, as Shreeve hints, the increasingly upright posture of each figure is not simply a visual matter but also a matter of quality: People who are upright are better than people who are not. There is a common verbal metaphor that equates an upright person with a good one. This change in posture is accompanied by an improvement in technology, with each figure holding a more advanced weapon than his predecessor. The exception is the final figure, 
who is unarmed but whose obviously groomed appearance testifies to his membership in an advanced civilization. Thus, the concept of technological progress through successive stages of deliberate refinement is activated as well. The March also activates other related concepts of progress. For instance, the arrangement of figures in step and in line suggests a march or parade and thus motion through a planned route to a final goal. These concepts can be rendered coherent by thinking of the image as a depiction of some process whereby each figure is the successor of its left-hand neighbor, improved with respect to a standard of quality towards a final goal.

By this analysis, the false impression given by the March results from the combination of demonstrative and rhetorical arguments. Specifically, the process suggested demonstratively is explained by the concept of progress activated rhetorically. In other words, the obvious changes in size, shape, and proportion between each figure is seen as caused by progress towards a goal (Shelley 1996, p. 66). This conclusion is false because the rhetorical argument happens to be, in a sense, unsound: Evolution is not progress towards a goal.

\section{Demonstrative and rhetorical arguments isolated}

The analysis of the March summarized in Section 2 relies upon a division of labor between largely visual and conceptual cognitive faculties. Support for this analysis could be given in the form of examples in which each mode of argument present in the original March is found in relative isolation but used to the same effect as before. In this Section, two descendants of the original are discussed that meet exactly these criteria.

The demonstrative argument of the March is adapted in a cigarette advertisement by duMaurier, resembling the image given in Figure 2 . The image presents a row of cigarette packs arranged in a sequence according to date. Visually, except for details of labelling, the packs are differentiated primarily by their position in a leftto-right sequence, with each one situated to appear to be in front of its leftmost neighbor.The rightmost pack is clearly in front of its neighbor and is presented open with some cigarettes exposed in an inviting way. As with the March, the effect is one of frames in a movie with the in-front-of spatial relation increased dramatically in the last frame. The process is a very simple one of a pack of smokes approaching the viewer and opening up. As with the March, the cause of this process is not depicted.

A rhetorical argument is provided explicitly by the accompanying text but is obviously incoherent. The caption "The evolution of quality" is no doubt meant to suggest that the cigarettes have undergone a successive set of improvements in quality over time and that one should buy them for this reason. But the logo "Classic quality", found beneath the row of packs, suggests that the current cigarettes retain the same quality they always had and that any change would be a diminishment of it. There are no visual cues that indicate that the sequence of 


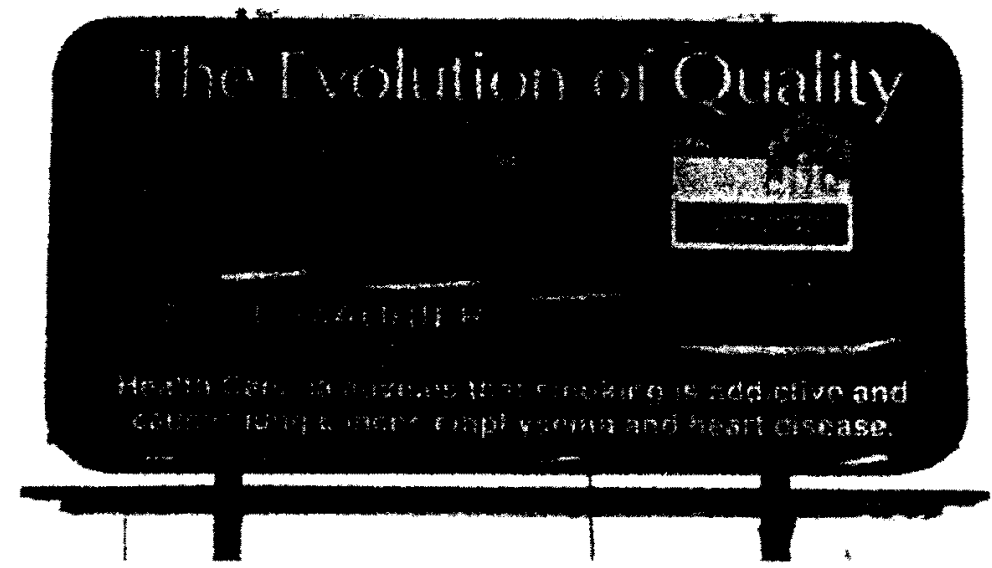

Figure 2. An advertisement for cigarettes, resembling one used by duMaurier in 1996. The packs in the duMaurier ad date, from left to right, from 1936, 1970, 1988, and 1996.

packs represents successive stages of improvement. Rather, it simply appears that duMaurier has been in the process of producing these smokes for many years.

In effect, this image relies principally on a stripped-down version of the demonstrative argument of the March. The image presents cigarette packs to the viewers as if they were watching a film of some cigarettes popping out of a single pack like a jack-in-the-box. The cigarettes are thus presented as the 'fruit' of this process and so become objects of interest and perhaps desire for viewers.

Conversely, the demonstrative argument of the March may be discarded and the concepts of the rhetorical mode activated by text alone. Consider the following 
description of the chief executives of IBM and Apple Computer giving a press conference to announce a new deal (Carroll 1993, p. 297):

Some IBMers joked that as they sat there up front and looked at the stage, they could see the entire sweep of history. There on the one end was Spindler, hulking, big-browed, surprisingly inarticulate. He represented Neanderthal man. Next to him was Cannavino, with his curly hair and goofy grin. Cannavino represented a step up the evolutionary ladder. Next came Kuehler, the cleancut, articulate, professional engineer. He represented modern man. Finally came Sculley, the wild-eyed marketing guy who had begun establishing himself as a visionary. He represented future man.

No visual presentation is needed. We are not even told whether the executives listed are arranged spatially in a left-to-right or right-to-left order. And we are left in no doubt that the sequence of executives represents a set of successive stages of development, "a step up the evolutionary ladder." Indeed, the vertical, ladder metaphor is inconsistent with the usual, horizontal spatial layout of the March. The description also appeals to stereotypes relating people's physical traits to their civilized quality: The hulking, big-browed man is the primitive whereas the cleancut, articulate man is the modern.

The outcome of this argument, that there exists a "sweep of history" with Sculley at its acme, is explicitly intended as a joke and not a serious conclusion. Nevertheless, this example shows that the rhetorical visual argument of the March can be abstracted from its original context and employed verbally to evoke the same concepts, namely a succession of stages culminating in an ultimate, end product.

The existence of these versions of the March, in which the demonstrative and rhetorical arguments of the original are isolated and employed separately, supports the contention that they worked together as described in Section 2. We can now move on to look at images in which the March is adapted and combined with other elements to produce new arguments.

\section{The March argument adapted}

Variations of the March image can not only support the analysis given earlier but can also illustrate another property of visual arguments, namely the tendency for the conclusion to change upon a change or augmentation of the premises. In this section, three offspring of the March are presented and analyzed to show how the image may be exploited in the service of conclusions alien to the original. The concept of a frame is given to capture how visual arguments may incorporate given sub-arguments just as verbal arguments may incorporate other verbal arguments.

In the March (Section 2), the conclusion that human evolution represents a process of stagewise, goal-directed improvement was characterized as the result of the conjunction of a demonstrative argument and a rhetorical one. The 
demonstrative argument suggested the action of a coherent process of change acting on the human figures portrayed, while the rhetorical argument explained this process as the result of progress. If so, then it should be possible to change the conclusion of this argument by altering its premises. Such an alteration is found in the image entitled Homersapien, where the rhetorical argument is changed to be incompatible with that of the original image.

This image (not shown for legal reasons) consists of a linear series of figures, Monkius eatalotis, Chimpus imbecilis, Ape-is stupidius, Neanderslob, and Homersapien, rendered in the distinctive manner of the animated TV show The Simpsons, arranged as in the March but dirty and overweight in appearance. The demonstrative argument is similar to that of the original March, showing a similar sequence of changes in height, proportion and posture. The rhetorical argument is, however, quite different than that conveyed by the original image. In particular, the first and last figures in the sequence, namely Monkius eatalotis and Homersapien, are each shown scratching their asses and indelicately munching half-peeled bananas. This salient non-change between the first and last figures cancels any notion that they are part of a succession of progressive stages in human development. And, in any case, Homersapien's dull and uncouth appearance would hinder the viewer from thinking of him as the final achievement of history. Thus, the rhetorical argument of this image is wholly at odds with that of the March and thereby blocks its conclusion. Instead, we are left to think that the visually evident process implies no qualitative advancement.

As with verbal arguments, the argument of the March may be adapted by putting it to work as part of a larger argument to establish a different conclusion. This goal can be accomplished visually by placing the March within a larger image, which I will refer to as a frame. A frame is an image into which another one is incorporated, with the effect of placing the smaller image in a context of new objects and visual relationships. A frame can thereby provide the additional premises needed for the larger argument to work. Such an augmented argument is shown in Figure 3.

In this figure, the March image is incorporated as the source domain of a disanalogy with an example of social progress or lack of it. The March is presented in the upper panel with a parallel row of cleaning ladies presented in the lower panel. The potential analogy between these two panels is initially supported by the similar posture of their left-hand figures but is ultimately canceled by a number of salient differences. First, the women in the lower panel do not change and remain on all fours throughout. Second, whereas the figures in the upper panel exhibit a confident posture, the women beneath display a decidedly unhappy facial expression. Third, whereas the figures in the top panel are involved in a biologically salient process, the women in the bottom panel are involved in a socially salient process of performing menial labor. Most important, however, is the fact that the bottom figures are women whereas the top figures are men (at least where their 


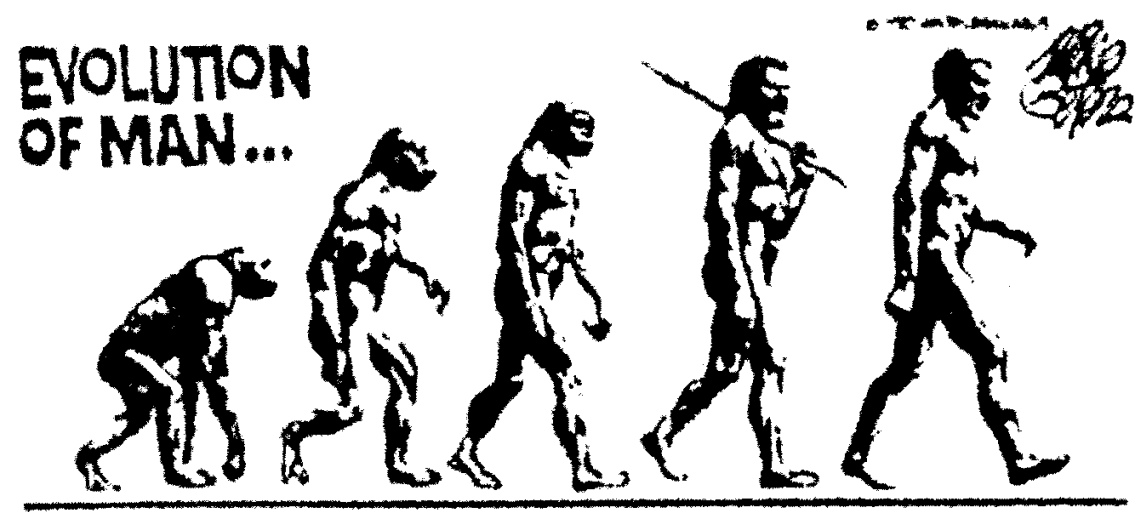

andwoman.
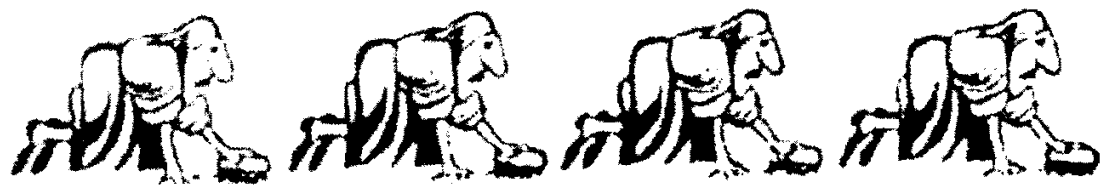

Figure 3. Women physically exploited by men, as represented by Mike Peters in the Dayton Daily News, 1980. C Tribine Media Services, Inc. All rights reserved. Reprinted with permission.

gender is discernible), a fact confirmed by the caption. This last difference suggests an explanation for the women's stagnation, namely that men have enjoyed progress because they are male whereas women have suffered stagnation because they are female. Furthermore, the depiction of the male figures as walking across the backs of the women suggests a verbal metaphor for exploitation. In other words, men have enjoyed progress directly at the expense of women. This hypothesis would also explain why the women are so clearly unhappy. The maintenance of a positive attitude by the males, in contrast, is explained by their disregard of the women's plight, a fact confirmed by the depiction of the men looking around at their own level rather than towards the women below. Finally, the ability of the men to both exploit the women and overlook their plight may be explained by appeal to the notion of progress implicit in the March image. In other words, it may be that biological progress is, in truth, an attitude that men have evolved over 
time which they use to rationalize their exploitation of women and to ignore the suffering that results. On this view, Peters' cartoon is ultimately understood as a kind of ironic critique of the original March. (Cf. the treatment of verbal irony by Wilson and Sperber 1992.) By cleverly placing the March within a larger image, the artist has exploited its message in the service of a wholly different conclusion.

(It is also possible to view the placement of panels as an instance of the artistic convention that higher-is-earlier. On this view, the women are meant to follow the men in temporal order. The implication here would be that men have used their progress, once achieved, to establish the social oppression of women. This view is supported by the fact that the women are clothed and use a tool and are therefore 'advanced' at their first appearance. However, this view does not account for the similarity of the left-most figures in each panel nor the salient differences and apparent irony mentioned above.)

Finally, the March may be adapted by altering it first, as with Homersapiens, and then placing it within a frame, as with Figure 3. Such an example is given in Figure 4.

In this figure, the frame consists of placing a version of the March within a "thought balloon." The artist uses this artistic convention to display a particular woman's mental imagery while reacting to a newspaper article entitled "U.S. election reveals widening gender gap!!" (This convention also explains why this version of the March appears at the top of the cartoon: not as an indication of dominance as in the previous example but because thought balloons go above or beside the thinker's head by tradition. This tradition is quite sensible in its own right since thought is closely associated with people's heads.) The woman has imagined an altered March in which men are depicted as having stagnated in a primitive condition, stooped, unkempt and fur-clad. There is an obvious disanalogy between their condition and that of the woman, who is erect, well groomed and attired, and holding a newspaper. As in the previous instance, this disanalogy is explained by a difference in gender, a "gender gap" according to the newspaper headline (and reinforced by the caption). So, the suggested inference is also as before, with the place of progress and stagnation reversed: Men have stagnated because they are male whereas women have advanced because they are female. This inference would conclude the visual argument were it not for the background fact that the 1996 U.S. Presidential election was known as the campaign of the "soccer moms" (who were white, middle-class, urban women who were perceived as the swing vote in the election due to their willingness to break with their Republican husbands to vote Democrat). This fact clearly explains the atavistic and rigidly-held posture of the men as a claim about their conservative social attitude, an instance of the metaphor of physical-posture-as-mental-attitude. The hypothesis of arrested social attitudes is confirmed by the men's failure to groom and attire themselves presentably, or to bother keeping up with the news. The derogatory nature of this hypothesis is evident in the puckered expression of disapproval directed by the woman toward the viewer. Thus, as with the previous 

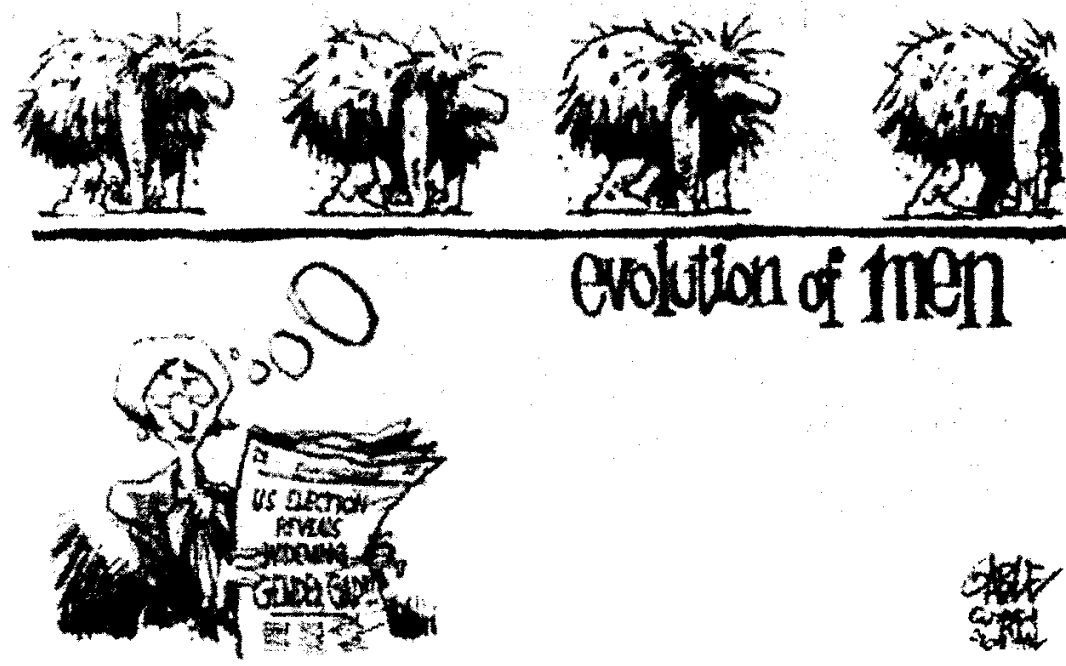

\section{erolution of men}

Figure 4. Women excelling men in influence, as represented by Gable in the Globe and Mail, 1996. The headline on the woman's newspaper reads "U.S. election reveals widening gender gap!!" Reprinted with permission from the Globe and Mail.

example, this image uses the March to address issues of social progress but comes to an opposite conclusion, i.e., that women surpass men in social influence rather than suffer oppression by them. The difference in the treatment of the March and the frame within which it is placed is key to the foundation of both arguments.

The examples discussed above show that the argument conveyed by the March image may be adapted to serve as a part of arguments aimed at very different conclusions. As such, it may be left intact or altered as required, and then placed within an appropriate frame to suggest the desired conclusion. These alterations and inclusions typically deal with the rhetorical argument of the original-that is, they play with the concept of successive stages of improvement, contrasting it with some form of stagnation in quality. The demonstrative argument, an argument to the action of a coherent process of change, is either simply canceled or left asis. There are at least two possible explanations for this focus on the rhetorical 
argument of the original. First, it may simply be easier to alter the rhetorical argument by a frame than to alter the demonstrative one. Second, as (Shelley 1996 , p. 67) notes, demonstrative arguments admit of only a narrow range of visual depictions. Thus, it may not be possible for an artist to alter the demonstrative argument too much and still expect the viewer to get the connection between it and the original March, a connection that the artists whose work is discussed here clearly wish us to perceive.

\section{Conclusions}

This case study of the March provides support for the analysis of it given by Shelley (1996). This image may be construed as a visual argument carried on in two modes simultaneously, namely the demonstrative and rhetorical modes. Changes in the content of the March, as exhibited by some of its descendants, can be construed as changes in one or the other modes of argument. Various alterations in the demonstrative or rhetorical modes suggest various, altered conclusions.

That the March may be viewed as a kind of argument is further supported by the fact that it may be incorporated into a frame image. The resulting, composite image may be read as an argument in which the argument of the original image (or some alteration of it) is composed with additional premises to suggest a novel conclusion. This sort of compositional property is also a central feature of verbal arguments. Perhaps it is not a coincidence that the frame images discussed here tend to operate on the rhetorical component of the March, since this component most closely resembles verbal arguments.

This study concentrates on the March image and some of its relatives. It is valuable to understand the argument that is apparent in this image because it is so ubiquitous and influential in the common understanding of evolution. But it is also valuable because it suggests that the method of analysis exemplified here may be applied to many other images so that the messages they appear to bear can be similarly illuminated and critiqued.

\section{Acknowledgments}

Thanks to the anonymous reviewers for comments on an earlier version of this article. This research is supported by the Social Sciences and Humanities Research Council of Canada.

\section{References}

Baigrie, B. S., editor (1996). Picturing knowledge: Historical and philosophical problems concerning the use of art in science. University of Toronto Press, Toronto. Carroll, P. (1993). Big blues: The unmaking of IBM. Crown Publishers, New York. Giere, R. N. (1996). Visual models and scientifc judgement. In Baigrie (1996), pages 269302. 
Gould, S. J. (1989). Wonderful life: The Burgess shale and the nature of history. W. W.

Norton \& Co., New York.

Groarke, L. (1996). Logic, art and argument. Informal logic, 18(2\&3): 105-29.

Howell, F. C. (1965). Early man. Time-Life Books, New York.

Moser, S. (1996). Visual representation in archaeology: Depicting the missing-link in human origins. In Baigrie (1996), pages 184-214.

Olson, L. C. (1991). Emblems of American community in the Revolutionary era: A study in rhetorical iconology. Smithsonian Institution Press, Washington.

Shelley, C. (1996). Rhetorical and demonstrative modes of visual argument: Looking at images of human evolution. Argumentation and Advocacy, 33(2): 53-68.

Shreeve, J. (1995). The Neandertal enigma: Solving the mystery of modern human origins. William Morrow and Company, New York.

Wilson, D. and Sperber, D. (1992). On verbal irony. Lingua, 87(1/2): 53-76.

Cameron Shelley Department of Philosophy, University of Michigan Ann Arbor, Ml 48109-1003 cshelley@umich.edu

\section{THE MONIST}

IN INTERNATIONAL JOURNAL OF GENERAL PHILOSOPHICAL INQUIRY

JULY 2001

VOL. 84, NO. 3

SINGLE ISSUE, US \$12

\section{THE EPIDEMIOLOGY OF IDEAS}

ADVISORY EDITOR: DAN SPERBER

ARTICLES

Daniel C. Dennett

LYND Forguson

Alvin L. Goldman

PhiLIP Kitcher

Ruth Gardett Milukan

F. C. T. MoORE

Asa Kasher \& Ronen Sadka
The Evolution of Cullure

Oxford and the "Epidemic" of Ordinary Language Philosophy Social Routes to Belief and Knowledge

Infectious Ideas: Some Preliminary Explorations

Purposes and Cross-purposes:

On the Evolution of Languages and Language

Scribes and Texts:

A Test Case for Models of Cultural Transmission

Constitutive Rule Systems and Cultural Epidemiology

Editor: Barry Smith, University at Buffalo, State University of New York

Single issues, $\$ 12$ postpqid. Annual subscription: institutions, US \$50; individuals, US \$30; make checks payable to THE MONIST, 315 Fifth Street, Peru, 1L U.S.A. 61354.

Website: http:/wings.buffalo.edu/philosophy/monist E-mail: philomon1 @ netscape.net 